\title{
PUBLICATIONS RECEIVED
}

Bilý, Milan, Intrasentential pronominalization and functional sentence perspective (in Czech, Russian and English) (= Lund Slavonic Monographs 1), Lund 1981, Slaviska Institutionen vid Lunds Universitet, 232 pp.

Garde, Paul, Grammaire russe, 1, Phonologie - Morphologie, (= Collection de Grammaires de l'Institut d'Études slaves - VII/1), Paris 1980, Institut d'Études slaves, 486 pp.

Gardiner, Duncan B., Intonation and music. The semantics of Czech prosody (= Physsardt Series in Prague Linguistics 2), Bloomington 1980, Physsardt Publications, $129 \mathrm{pp}$.

Issatschenko, Alexander, Geschichte der russischen Sprache, 1. Band, Von den Anfängen bis zum Ende des 17. Jahrhunderts, Heidelberg 1980, Carl Winter Universitätsverlag, 348 pp.

Jurkowski, Marian, Bibliografia rusycystiki polskiej 1945-1975. Jezykoznawstwo, Warszawa 1976, Państwowe wydawnictwo naukowe, $172 \mathrm{pp}$.

Mel’čuk, Igor A., Studies in dependency syntax, Ann Arbor 1979, Karoma Publishers Inc., $163 \mathrm{pp}$.

Studia Slavica Gunnaro Jacobsson sexagenario a discipulis oblata (= Slavica Gothoburgensia 7), Göteborg 1980, Acta Universitatis Gothoburgensis, $115 \mathrm{pp}$.

Жолковский, А. К. и Щеглов, Ю. К., Поэтика выразительности. Сборник статей (= Wiener slawistischer Almanach, Sonderband 2), Wien 1980, Institut für Slawistik der Universität Wien, $256 \mathrm{pp}$.

Russian Linguistics 6 (1981) 167. 0304-3487/81/0061-0167\$00.10.

Copyright (C) 1981 by D. Reidel Publishing Co., Dordrecht, Holland, and Boston, U.S.A. 